\title{
THE DETECTION OF MINUTE QUANTITIES OF UNSATURATED HYDROCARBONS IN PETROLATUM OIL.*
}

BY C. H. BRIGGS AND W. L. IRWIN.

The recent discovery of the value of petrolatum oil as an intestinal lubricant has increased the consumption of this oil enormously. Because of the large doses used in this treatment the purity of the oil is important. It is claimed that unsaturated hydrocarbons are liable to be broken up in the body with the formation of poisonous products, hence, the presence of these compounds in petrolatum oil for internal use should be rigorously guarded against.

It is well known that commercial petrolatum oils before being purified contain considerable proportions of unsaturated hydrocarbons. These unsaturated compounds react readily with concentrated sulphuric acid, and the usual method for determining if an oil has been properly purified is to treat it with concentrated sulphuric acid and note the color formed.

The last British Pharmacopœia requires that when 3 mils of the oil are heated with an equal volume of sulphuric acid in a test-tube, placed in boiling water for ten minutes, and frequently shaken, the acid layer should not be darker than pale brown.

A sulphuric acid test for petrolatum oil is to be included in the U. S. P. IX. ${ }^{1}$ The test as usually applied in this country requires that 5 mils of the oil be shaken at frequent intervals, during ten minutes, while warming on a water-bath, with 5 mils of sulphuric acid, in a glass-stoppered cylinder.

It has recently been proposed that a mixture of equal parts of nitric and sulphuric acids be used for this test.' This mixed acid test has been given a great deal of publicity during the last year, and it has been claimed that it is a more delicate test for unsaturated hydrocarbons than the sulphuric acid test. The facts of the matter are that the mixed acid test can only be applied to oils containing hydrocarbons of the naphthene series and it must not be used on oils of the methane series.

This mixture of concentrated nitric and sulphuric acids is a very strong nitrating agent, and Zaloziecki and Frasch ${ }^{2}$ have shown that it will nitrate hydrocarbons of the methane series which contain side chains, forming nitroparaffins having a yellow color. Now, these hydrocarbons having side chains are completely saturated and are not acted on by concentrated sulphuric acid alone. They are present to a small extent in all oils of the methane series and are perfectly harmless. All the oils produced in the eastern and central parts of the United States are of the methane series, and only those oils produced in California are of the naphthene series. Hence, the mixed acid test should only be used on California oils and is not applicable to oils obtained from other sections of this country.

It occurred to the writers that the application of the bromine test for unsaturated compounds to petrolatum oils for internal use would perhaps be a better and more reliable means of detecting these compounds.

The bromine absorption value has been used by McArthur ${ }^{3}$ for determining the amount of unsaturated hydrocarbons in shale and lubricating oils. This method consists in allowing the oil to react with an excess of bromine in carbon

* Presented before Pharmaceutical Section of American Chemical Society, Apri1, 1916.

2 Jotrnat. A. Ph. A., vol. iv, 994.

Berichte 35, 390.

'J. Soc. Chem. Ind., 1888, 7, 65. 
disulphide under certain conditions, and determining the amount of bromine absorbed.

We attempted to apply this method to petrolatum oils for internal use, but the amount of unsaturated hydrocarbons in these oils is so small that traces of bromine absorbed by the carbon disulphide appeared to vitiate the results. It was found, however, that by using carbon tetrachloride in place of the carbon disulphide and making some other modifications to adapt the test to conditions, the bromine test gives reliable results for the detection of unsaturated hydrocarbons in petrolatum oils. Furthermore, the test seems to be quantitative and hence the amount of such unsaturated hydrocarbons can be estimated approximately.

The reagents required for the test are as follows:

1. Purified carbon tetrachloride: Add bromine to commercial carbon tetrachloride until the color remains permanent and allow to stand for three or four hours. Add potassium hydroxide in small pieces and allow to stand with occasional agitation until the carbon tetrachloride gives no test for bromine. Distil off the carbon tetrachloride, leaving a few pieces of the potassium hydroxide in the flask. Test distillate for absence of bromine.

2. $\frac{\mathrm{N}}{500}$ bromine solution: Dissolve sufficient bromine in purified carbon tetrachloride to make an $\frac{\mathrm{N}}{500}$ bromine solution approximately.

3. $\frac{\mathrm{N}}{500}$ sodium thiosulphate solution.

4. Starch and potassium iodide solution for indicator: 5 grammes potassium iodide, 5 mils 2 percent starch solution, and 500 mils of distilled water.

To make the test, take 5 mils of oil in a 50 mil glass-stoppered cylinder, add 5 mils purified carbon tetrachloride and 5 mils of the $\frac{N}{500}$ bromine solution. Shake and allow to stand fifteen minutes in the dark. Now, add about 3 mils of starch-potassium iodide indicator and titrate with $\frac{N}{500}$ thiosulphate solution until the color is completely discharged from both layers of the mixture. It is important to shake vigorously after each addition of the thiosulphate solution.

A blank consisting of 5 mils of the $\frac{N}{500}$ bromine solution and 5 mils of the purified carbon tetrachloride solution is run at the same time. The difference in the amount of $\frac{N}{500}$ thiosulphate solution absorbed by the blank and by the sample is the amount of $\frac{\mathrm{N}}{500}$ bromine absorbed by 5 mils of the oil.

It is important that the carbon tetrachloride be free from moisture and that the cylinders be perfectly dry.

In order to test out the leading brands of petrolatum oil on the market, ten samples were obtained from one of the largest drug stores in Detroit. These samples were assayed for unsaturated hydrocarbons by the bromine test as described above, and were tested by the sulphuric acid test, and also by the mixed acid test. These results are incorporated in the following table:

\begin{tabular}{|c|c|c|c|c|c|}
\hline & $\begin{array}{l}\text { Mils of } \underset{500}{N} \text { bromine } \\
\text { solution absorbed. }\end{array}$ & $\begin{array}{l}\text { Relative position in } \\
\text { bromine test. }\end{array}$ & $\begin{array}{l}\text { Reiative position } \\
\text { in } \mathrm{H}_{2} \mathrm{SO}_{4} \text { test. }\end{array}$ & $\begin{array}{l}\text { Relative position } \\
\text { in mixed acid test. }\end{array}$ & $\begin{array}{l}\text { Relative position } \\
\text { as to taste. }\end{array}$ \\
\hline A & $\ldots \ldots \ldots \ldots . .5$ & 1 & 2 O.K. & 2 & 1 \\
\hline B & $\ldots \ldots \ldots \ldots$ & 2 & 3 O.K. & 3 & 3 \\
\hline C & $\ldots \ldots \ldots$ & 3 & 1 O.K. & 1 O.K. & 2 \\
\hline $\mathrm{D}$ & $\ldots \ldots \ldots \ldots$ & 4 & 4 O.K. & 6 & 9 \\
\hline$E$ & $\ldots \ldots \ldots \ldots$ & 4 & 7 & 5 & 4 \\
\hline $\mathrm{F}$ & $\ldots \ldots \ldots \ldots$ & 4 & 8 & 8 & 8 \\
\hline G & $\ldots \ldots \ldots \ldots \quad 1.2$ & 7 & 6 & 7 & 7 \\
\hline $\mathrm{H}$ & $\ldots \ldots \ldots \ldots \quad 2.2$ & 8 & 5 & 4 & 6 \\
\hline$I$ & $\ldots \ldots \ldots \ldots, \quad 2.3$ & 9 & 9 & 8 & 5 \\
\hline$J$ & $\ldots \ldots \ldots \ldots \ldots 19.0$ & 10 & 10 & 10 & 10 \\
\hline
\end{tabular}


It will be noted that nine samples absorbed from .5 to 2.3 mils of $\frac{\mathrm{N}}{500}$ bromine and that sample J absorbed 19 mils of $\frac{N}{500}$ bromine. Sample J was a very poor grade of Russian oil. Six of the samples absorbed less than $1 \mathrm{mil}$ of $\frac{\mathrm{N}}{500}$ bromine for 5 mils of the oil and this would appear to be a satisfactory requirement for unsaturated hydrocarbons.

When tested by sulphuric acid test, the ten samples showed a wide variation in color and only four would meet the requirements of this test as usually applied.

The three oils which showed the least amount of unsaturated hydrocarbons by the bromine test were also the three best oils by the sulphuric acid test. There does not, however, appear to be a strict relation between the amount of unsaturated hydrocarbons in the oil and the color which is formed by the sulphuric acid test. This would indicate that there are other substances than unsaturated hydrocarbons that are reacted on by the sulphuric acid.

When tested by the mixed acid test, the samples also showed a wide variation in color and only one sample met the requirements of the test. As was to be expected, this sample was an oil of the naphthene series.

The taste of the different oils was also noted, but there did not seem to be any relation between the unsaturated hydrocarbons and the taste of the oil.

Because of the very small quantity of bromine absorbed by these oils, the writers have attempted to calculate approximately the amount of unsaturated hydrocarbons present. Assuming that the unsaturated hydrocarbons in the petrolatum oils have a composition of $\mathrm{C}_{18} \mathrm{H}_{36}$, which hydrocarbon would have approximately the correct boiling point, then $1 \mathrm{mil}$ of $\frac{\mathrm{N}}{500}$ bromine would be equivalent to $1 / 4$ milligramme of the unsaturated hydrocarbon. Five mils of the best petrolatum oils would therefore contain less than $1 / 4$ milligramme, or less than 0.005 percent, of unsaturated hydrocarbons.

It is inconceivable that this small quantity of unsaturated hydrocarbons in liquid petrolatum would have any injurious effect when the oil is taken internally.

Great credit is due American chemists and American manufacturers for the degree of perfection they have reached in the purification of American liquid petrolatums.

Chemical Laboratory, Parke, Davis \& Co., Detroit, Mich., April 14, 1916.

\section{ADSORPTION OF PEPSIN FROM AQUEOUS SOLUTION BY ALUMINA.}

About 12.4 percent of the total pepsin present in aqueous solution is removed by digestion with alumina. This adsorbed pepsin cannot be recovered by repeated extraction of the alumina, to which it adheres, by means of warm water. The filtrate from the digestion with alumina, when again treated with that substance, fails to part with any more of its pepsin. Pepsin is stated to be partly crystalline. (These results seem to point to the fact that argillaceous filtering media should not be employed for brightening preparations of pepsin.) - M. A. Rakuzin and E. M. Braudo (J. Russ. Phys. Chem. Soc.; Chem. Abstr., 1915, 9, 3071 ). 